\title{
Fenomenologia do maravilhoso na literatura italiana
}

\author{
Erminia Ardissimo (Universidade de Torino, Torino, Itália) \\ erminia.ardissino@unito.it \\ Tradução de Silvana Scarinci (UFPR, Curitiba, PR) \\ silvanascarinci@yahoo.com.br
}

\begin{abstract}
Resumo: 0 maravilhoso na literatura italiana assume diversas formas. Eu pretendo apresentar aqui três tipologias, escolhidas por serem arquetípicas e por explicarem o desenvolvimento futuro do gosto literário italiano. Em primeiro lugar, Dante: em sua obra, o nível epistêmico do sobrenatural se sobrepõe ao nivel do natural. Beatriz, a mulher-anjo, pertence ao mundo real, mas através de suas qualidades conecta este mundo ao mundo celeste. Ela é conhecida por ser uma manifestação do divino, um milagre. Em segundo lugar, episódios de magia nos poemas cavalheirescos sublinham o imprevisível e a surpresa, o que sempre trazem novos rumos às vidas das personagens, às vezes surgem como soluções, outras vezes desviam o herói de seu destino correto. Em Orlando Furioso, a mágica também revela os desejos obscuros das personagens e seres humanos; trata-se de uma espécie de ciência da imaginação. Em terceiro lugar, na literatura de viagem, o maravilhoso é um tema recorrente, já que a viagem é um meio de se encontrar com o desconhecido, o inacreditável, o prodigioso, desde o Milione de Marco Polo. No início da era moderna, uma nova epistemologia e desencantamento tomam o lugar das analogias e da mágica, mas o maravilhoso não desaparece, ao contrário, adquire ainda maior importância com a nova ciência. Concluirei minha fala com algumas considerações sobre a maravilha na música presente na literatura do século XVII.
\end{abstract}

Palavras-chave: Maravilhoso; Dante; Ariosto; Literatura de viagem; Barroco.

\section{Phenomenology of Italian Literary Marvelous}

Abstract: The marvelous in Italian literature assumes many forms. I intend to present here three typologies, chosen because they are archetypal and explain the future development of Italian literary taste. First Dante. In his work the epistemic level of the supernatural overlaps the level of the natural. Beatrice, the woman-angel, belongs to the real world, but through her qualities connects this world to the heavenly one. She is said to be a manifestation of the divine, a miracle. Second: episodes of magic in the chivalric poems underline the unforeseeable and the surprising, which always divert the lives of the characters, sometimes offering solutions, other times turning the hero aside from the right path. In Orlando Furioso magic also reveals the hidden wishes of characters and human beings, it is a kind of science of the imagination. Third: in travel literature the marvelous is a recurrent theme, because travel is a way of encountering the unknown, the unbelievable, the prodigious, since Marco Polo's Milione. At the beginning of the modern age new epistemology and disenchantment replace analogies and magic, but the marvelous does not disappear, on the contrary it acquires even more importance with the new science. I will end with few considerations on the marvelous in music in Seventeenth century literature.

Keywords: Marvelous; Dante; Ariosto;Travel Literature-Baroque.

\section{É do poeta o fim a maravilha...}

Colocar em evidência o verso de Giambattista Marino no programa desta Semana de Música - que tem por tema a meraviglia, - não é somente útil, mas também valoriza um poeta que foi definitivamente consciente da ligação entre poesia e música e dela fez um princípio de poética. E esta visão pode se estender também a sua época, expressando-se na música com invenções tão significativas a ponto de criar dois gêneros, o melodrama e o oratório, que se pode chamar de antonomásias do Barroco. A mú- sica adquire naquele século um novo estatuto, abandonando as tradições antigas e medievais que aproximavam a música das esferas celestes com matriz pitagórica. Por um lado, se há uma nova abordagem da música em nível empírico com o estudo dos fenômenos acústicos e físicos, por outro, ela é reconduzida à esfera da psique humana como nas expressões dos tormentos da alma e dos afetos interiores. Por causa deste aspecto e pelo interesse por uma palavra expressiva, a música se associa à poesia; 
tanto que De Sanctis, ao escrever sobre literatura italiana daquele século, pôde dizer que a poesia "convertida em palavra que soa, se transforma na música e no canto" 1 (DE SANCTIS, 1981, p.735).

0 verso "é do poeta o fim a maravilha" pertence a um escrito polêmico de Marino, voltado contra seu adversário na corte de Sabóia, o genovês Gaspare Murtola, que em 1608 havia publicado um poema hexâmetro intitulado $L a$ creazione del mondo, (A criação do mundo) cujas páginas dedicadas aos leitores proclamava que seu "fim" era "fazer nascer a maravilha" 2 com a contemplação das obras da criação divina e com estas "revelar grandiosamente a providência de Deus (MURTOLA, 1606)." 3 Em Torino do início dos Seiscentos, onde Marino tinha recém aportado, mas onde também desejava fixar-se, com brilhante treinamento poético e cortesão que o havia levado de Nápoles a Roma e a Ravena-Bolonha e o levaria, depois de Torino a Paris, introduzir-se entre os poetas já estabelecidos não devia ser fácil. Entre Murtola e Marino nascia uma áspera troca de sonetos ironicamente malévolos, e ataques ainda mais violentos que culminaram num tiro de pistola que Murtola disparou contra Marino, errando o alvo. Os 81 sonetos de Marino contra Murtola (Le fischiate - "Os assobios") foram depois editados em 1626 (Francoforte, G. Beyer) sob o título Murtoleide, com os sonetos de Murtola (Le risate - "As risadas").

0 objetivo de Marino era o de vilipendiar seu rival com a paródia, e bastará observar os tercetos de onde foi retirado o verso, para convencermo-nos do que se tratava:

\author{
ASSOBIO XXXIII \\ É do poeta o fim a maravilha \\ (falo do excelente, não do tolo); \\ quem não sabe surpreender, que retorne ao estábulo. \\ Eu nunca leio sobre o cavalo e a alcachofra, \\ que não arca por estupor os cilios, \\ como pode ser um homem tão arruaceiro.
}

(MARINO, 1967, p.852-853)

Murtola causa estupor porque insere no poema um mundo extremamente banal que se revela com inaudita comicidade. Marino retoma então o objetivo do genovês para torcer-Ihe o sentido; não são as obras da criação, nem as alcachofras nem os cavalos que fazem a maravilha do poeta. Esta é matéria do poeta arruaceiro. Distinta é a maravilha do excelente: as invenções da retórica e da métrica, as argúcias e os conceitos, as formas e as organizações dos novos conteúdos.

A reconstrução da poética marinista pode se apoiar somente em afirmações ou defesas esporádicas, pois ele, como os poetas de seu século, repudiou o uso de declarações de poética e debates teóricos, tão comuns nos Quinhentos. Ao invés disto, estava interessado no consenso dos leitores e fazia da satisfação do gosto do público seu principal objetivo. Quando teve necessidade de defender sua prática poética, Marino apelou sempre a seu sucesso frente aos leitores. Sua poesia tem como objetivo o delei- te, pois isto era, disse ele, segundo Aristóteles, o objetivo da poesia, e o meio para suscitá-la é a maravilha, a surpresa contínua. Em carta a um amigo, o poeta Girolamo Preti, escreve: "Pretendo saber as regras melhor que todos os pedantes juntos, mas a verdadeira regra (coração meu belo) é saber romper as regras no momento e lugar apropriados" (MARINO, 1996, p.396). ${ }^{5}$ Nos seus versos busca um prazer que contemple o efeito intelectual de surpresa, além do efeito melodioso. Em outra afirmação sua: "Os poetas que ditam rimas sem vivacidade, fabricam cadáveres, não poesia" (MARINO, 1996, p.420). ${ }^{6}$ Marino deseja que suas rimas sejam uma constelação "cintilante de poesia viva." 7 Seu objetivo é mostrar fantasia e versatilidade, gosto pela raridade e pela novidade. Serve-se do repertório clássico e quinhentista, o qual conhece bem, renovando-os nos temas e nas formas. Com estes principios, sua poesia torna-se rapidamente representativa do gosto do século. Com um estilo que ele mesmo define como "suave, belo e atraente," 8 com material novo, feito de "suave gentileza" (MARINO, 1986, p.84), ${ }^{9}$ Marino quer acomodar-se ao humor de seu século para satisfazer 0 apetite do público - e soube alcançá-lo.

Para ilustrar o procedimento da maravilha de Marino, observemos inicialmente duas oitavas, nas quais representa Amor, em seu maior poema, L'Adone. 0 deus, que já na tradição petrarquista, gela e inflama, é representado aqui com suas conotações tradicionais, mas organizados num surpreendente acúmulo de oximoros.

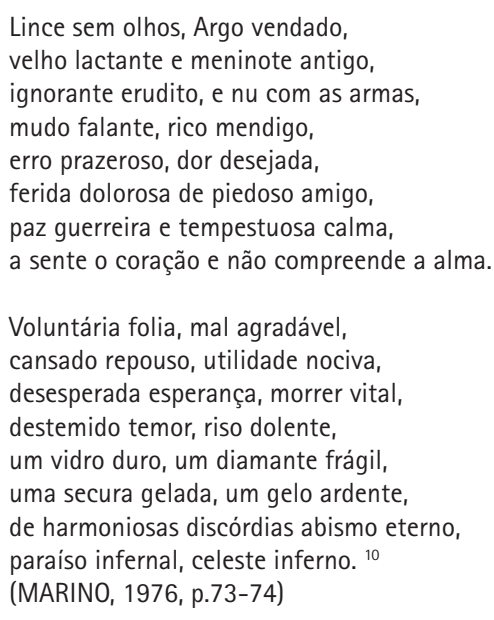

Nesta leitura é impossível não nos surpreendermos com a profusão de oximoros, dois para cada verso, durante sete versos, alguns construídos já sob o princípio do próprio oximoro (oximoro ao quadrado, portanto!). Este acúmulo "não responde somente ao gosto barroco pela eflorescência verbal e pelos catálogos infinitos, mas também pela natureza polissêmica daquilo que Marino busca definir" (BATTISTINI, 2007, p.167-183). ${ }^{11}$ Já o oximoro é de fato uma figura que rompe o andamento retilíneo pelo pendular, de oscilação entre dois pólos opostos que não se anulam, mas permanecem ambos presentes. As duas oitavas são um dos pontos de maior tensão retórica no poema, mas normalmente o estilo de Marino é caracterizado pelo gosto e elegância e pela renúncia a graus extremos do 
concettismo. Bianconi, historiador da música, escreve que Marino deve "seu imenso sucesso musical justamente à moderada 'mediocridade' de suas invenções de conceitos e metáforas, em relação a seus colegas mais ousados nas metáforas" (BIANCONI, 1991, p.13). ${ }^{12}$

Precocemente consciente das novidades poéticas, Marino apresenta-se ao grande público em 1602 com uma coleção de poesias, a qual deu então o título, na edição de 1614: Lira. A outra coleção de idílios chamou Sampogna, demonstrando estar consciente de que a música tornara-se uma referência inescapável para a escrita poética daquele tempo. Sobre a importância da música deu provas também na sua escrita ao metaforizar num conceito - a música precisamente - um tema religioso como as últimas palavras de Cristo na cruz, numa de suas Dicerie sacre ("Discursos sacros"), que é um agregado de erudição e conceitos sobre o tema musical. Em Adone são notáveis as oitavas nas quais representa a mais variável e natural das músicas, o gorgeio do rouxinol, e até a voz das cantoras mais famosas da época (MARINO 2007, VII, 33 e 88). Marino foi assim objeto de muita atenção por parte dos compositores, que transformaram frequentemente em música os seus versos, facilitado pela natureza de sua palavra poética que respondia às novas exigências da cultura do momento. Até a primeira coleção de 1602 podemos notar as características que tanto facilitaram a adaptação (talvez antes da publicação) de seus versos. Tomemos um madrigal,

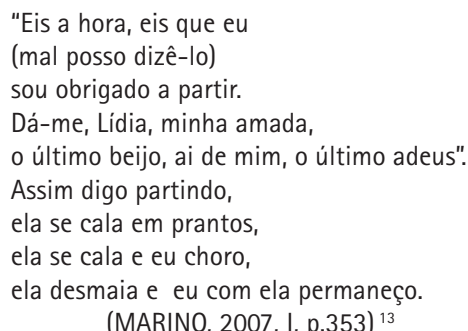

A composição poética chamada madrigal, inaugurada por Petrarca, permanecendo como um gênero variável da líri$\mathrm{ca}$, foi totalmente renovado por Marino, fazendo prevalecer os versos settenari em relação aos endecasillabi (como no madrigal citado acima). Deste modo, as anáforas vêm mais fortemente marcadas, e estas se tornam também refrões musicais. No pequeno diálogo fica implícito uma dramaticidade, que se estende até o surpreendente final. São evidentes as antíteses, os refrões, que aumentam os valores emocionais do texto e posteriormente do canto. Sobre estes, pode-se criar facilmente ritornelos, antecipações, repetições, rompendo também os versos.

Mas para compreender, no entanto, o escopo do debate que se trava em torno do maravilhoso na literatura italiana, deve-se olhar outras modalidades, outros períodos e outros autores. 0 maravilhoso está obviamente presente desde suas origens, nos poetas do Dolce Stil Novo, nos romances medievais, nos relatos de viagens, na hagiografia, nas novelas, etc. A categoria do maravilhoso pertence verdadeiramente a todos os gêneros, assim como naqueles em que o critério dominante da invenção é o realismo ou a narração baseada historicamente sobre fatos realmente ocorridos. 0 maravilhoso de fato irrompe algumas vezes nas narrações para indicar o evento essencial e surpreendente ou a qualidade prodigiosa de um personagem ou de um lugar ou de um objeto que Ihe tornam precisamente dignos de atenção narrativa.

Se a história da literatura ocidental, como escreveu Auerbach em Mimesis, é a história de um aproximar-se progressivo das categorias da verossimilhança e de suas elaborações, a história literária do maravilhoso pode, inversamente, reassumir a progressiva redução de seus espaços e de sua presença, para dar lugar às dimensões do quotidiano e do ordinário. Mas isto não desaparece, porque está ligado à aspiração humana de ver além do conhecido, que sempre encontrou e sempre encontrará elementos de surpresa, talvez na infinidade do espaço ou no breve suspiro da intimidade amorosa. A afirmação dos gêneros que trazem à tona o fantástico, como a fábula no Seiscentos ou a ficção científica no Oitocentos, oferecem de fato espaços literários inesperados para o maravilhoso. Hoje temos um retorno ao mágico com Harry Potter e suas histórias, e isto também pode ser uma homenagem à recriação inexaurivel do maravilhoso, que é de fato uma categoria antropológica e literária, que encontra sempre vida nova e novos meios expressivos.

A reação do sujeito que olha ou assiste ao evento que o maravilha e que como espectador escuta e acolhe em si as ações multiformes que provocam sua alma vem de Dante, em seu tratado filosófico, Convivio, indicada como uma qualidade inerente da adolescência e definida como um de seus signos de nobreza. Esta reação, junto com 0 pudor e o recato, é colocada no âmbito da vergonha, que é "profundamente necessária ao bom embasamento de nossa vida", ${ }^{14}$ diz Dante, porque "[...] naquela idade é necessário ser reverente e desejoso do saber; naquela idade é necessário ser controlado, de modo que não se transgrida; naquela idade, é necessário ser penitente na falta, de modo a que não se ouse falhar". ${ }^{15}$ Assim, ao definir estas paixões da alma, fala do estupor como "[...] uma surpresa da alma, pelas grandiosas e maravilhosas coisas vistas ou ditas ou de alguma forma escutadas: pois, enquanto parecem grandiosas, tornam-se reverentes aqueles que o escutam; enquanto parecem miraculosas, desejosos de compreendê-los" (DANTE, 1988, IV, XXV, p.1-5). ${ }^{16}$

A primeira maravilha da literatura italiana que merece nossa atenção emerge, de fato, justamente de um texto de Dante e de uma experiência adolescente: Beatriz. $\mathrm{Na}$ Vita Nuova, Beatriz, depois do primeiro encontro, surge para Dante como uma criatura excepcional. A lírica amorosa já havia falado frequentemente da maravilha suscitada no amante pela contemplação da mulher amada, com os consequentes suspiros e lamentos, dor e morte. Mas Dante vai mais adiante, definindo a mulher como maravilha em si mesma, como criatura além dos limites 
humanos. 0 primeiro encontro com a menina de oito anos conturba os espíritos que controlam a vida do eu narrador (espírito racional, espírito sensitivo e espírito animal), que aparecem contrastados em sua atividade normal, colocados ora sob a soberania de um Deus potentíssimo, Amor, que os obriga a ver frequentemente "aquela anjinha juveníssima": 17 "[...] eu, em minha infância, muitas vezes a estive buscando, e a mirava com comportamento tão nobre e laudatório, que certamente dela se podia usar aquelas palavras do poeta Homero: 'Ela não parece filha de homem mortal, mas de Deus" ${ }^{18}$ (DANTE, 1996, I, p.9). 0 verbo "parece" não indica aqui algo subjetivo, mas algo que se apresenta à vista do sujeito com as conotações de uma realidade objetiva: parecia ser filha de Deus.

Beatriz é, portanto, o prodígio, ou o evento sobrenatural que entra no cotidiano de Dante para Ihe revelar uma dimensão inesperada da existência. Dante usa neste caso para Beatriz a definição que Homero havia usado para Heitor (e que Dante conhecia através da citação de ARISTÓTELES (1983, VII, 1, 1145a) para indicar exatamente a virtude sobre-humana contrária à bestialidade, ou seja, uma virtude heróica e divina. A divindade de Beatriz é também expressa em sua qualidade angelical. A comparação da mulher amada a um anjo não é uma novidade, já Guido Guinizelli, - a quem Dante estima como "o sábio" 19 (DANTE, 1996, XI, 1), "seu pai e dos outros poetas" 20 (DANTE, 1994, XXVI, 97-98) - no final da canzone, Al cor gentil rempaira sempre amore, ("Ao coração gentil cura sempre o Amor") que é o programa do Dolce Stil Novo, diz que o amante poderá desculparse diante de Deus na prestação de contas final porque a mulher, justamente, "tem do anjo a semelhança / como se fosse de Teu reino." ${ }^{21}$ Mas Dante vai além da semeIhança e proclama a identidade entre o anjo e a mulher: Beatriz é "anjinha juveníssima." 22 Ainda que 0 adjetivo ofereça uma conotação de realismo e a forma feminina designe concretude a este anjo, é justamente a qualidade reconhecida que diferencia Beatriz das outras muIheres, o amor que Dante expressa por ela, distinto de um amor erótico e perturbador. Esta sua natureza the permite ser guiada por uma vida que busca elevar-se a Deus, é a maravilha da qual Deus quer servir-se "para fazer novas coisas" ${ }^{23}$ (DANTE, 1996, X, 22).

Beatriz é portadora de beatitude, como diz seu nome, justamente porque pertence a dois mundos, o humano e o divino. A Vita nuova é escrita como um livro da memória, pois Dante sabe, desde o princípio, que Beatriz é destinada à morte precoce, que não será objeto de amor, ou ao menos não daquele amor de que se inundavam os sonhos e as cartas dos poetas corteses. Beatriz depois de revelar sua natureza miraculosa, morre, obrigando o amante a descobrir a verdadeira natureza do amor. A mulher é em si mesma amor: "E quem quisesse sutilmente considerar, aquela Beatriz chamaria Amor, por tanta semelhança" ${ }^{24}$ (DANTE, 1996, XXIV). Com sua morte, Beatriz não desaparece, mas se define. Se Dante esquece seus votos, é ela que o estimula até o final para atingir seu objetivo que se realiza poeticamente somente no último canto da Divina Commedia, ou com a visão divina. Beatriz é, portanto da mesma natureza daquele "amor que move o sol e as outras estrelas" 25 (DANTE, 1997, XXXIII, 146). Como demonstrou Singleton, na base desta identificação dantesca da mulher e de Amor, está o versículo do Evangelho de São João: Deus caritas est ("Deus é caridoso"). Com Beatriz, Dante resolve a contradição entre o amor carnal e o amor espiritual, 0 amor por Beatriz não é jamais contrário ao amor por Deus.

No Canto Donne ch'avete intelletto d'amore ("Mulheres que haveis o intelecto de Amor") que assinala o início dos cantos de louvor, a mulher é elogiada por meio de uma dramatização, que vê em cena Deus, os anjos e Amor, que disputam Beatriz. Diante de Deus, "um Anjo, clama o divino intelecto e diz: 'Sire, no mundo se vê maravilha no ato que procede de uma alma que enfim aqui encima resplandece" ${ }^{26}$ (DANTE, 1996, XV, 18), ou atribui a Beatriz a dignidade de ser similar às criaturas sobrenaturais, superando a solução de Guinizelli, na qual a muIher disputava o louvor a Deus e à Virgem. Aqui, ao invés disto, se atinge a paridade entre a criatura que é ainda terrena e a celeste. Uma paridade que chega ao ponto de identificar Beatriz com Cristo. Ao ver numa visão a chegada da mulher de Guido Cavalcanti, monna Vanna ${ }^{27}$ ou Giovanna ou Primavera, com a admirável Beatriz, Dante antecipa aquilo que será na realidade, a chegada de Beatriz como Cristo, anunciada por Joana, como Cristo havia sido anunciado por São João. Como São João "precedera a verdadeira luz dizendo 'Ego vox clamantis in deserto: parate viam Domini" ("Eu sou a voz do que clama no deserto: Endireitai o caminho do Senhor") assim Monna Vanna precedeu Beatriz que é Amor. 0 soneto que transforma em poesia esta visão, de fato atribui a Beatriz a definição de maravilha, que devemos aqui ver em sua acepção de criatura miraculosa: "Eu vi monna Vanna e monna Bia / virem em direção de lá onde eu estava / uma ao lado da outra maravilha" ${ }^{28}$ (DANTE, 1996, XV, 7). E de fato, na sucessiva comparação de Beatriz lhe é atribuída a qualidade de milagre:

Diziam muitos, assim que passara ela: "aquela não é uma muIher, mas uma dentre os belíssimos anjos do céu". E outros diziam: "Aquela é uma maravilha; que bendito seja o Senhor que tão miraculosamente sabe operar!" Eu digo que ela se mostrava tão gentil e tão plena de todos os deleites, que aqueles que a miravam compreendiam em si mesmos uma doçura honesta e tão suave, que dizê-lo não sabiam; ninguém podia mirá-la, sem que nada fosse conveniente senão suspirar. Estas e outras miraculosas coisas dela procediam virtuosamente. Onde eu nisto pensando, querendo retomar o estilo de seu louvor eu decidiria dizer palavras nas quais eu desse a entender seus miraculosos excelentes atos [...] ${ }^{29}$

(DANTE, 1996, XVII, 2-3, grifo nosso).

O louvor a Beatriz declara a natureza divina da mulher miraculosa, "que por algo vinda / do céu à terra a milagres mostrar" 30 (DANTE, 1996, XVII, 6). 0 plano epistêmico do sobrenatural se sobrepõe ao plano epistêmico do natural através de um personagem que, pertencendo ao mundo do real, por sua qualidade constitui um elo de união, uma manifestação do divino que irrompe no natural. 
Se em Dante o maravilhoso é uma forma de revelação do sobrenatural pela via do miraculoso, o maravilhoso do poema cavalheiresco é uma manifestação do sobrenatural pela via da magia, seja essa de origem demoníaca (na maioria dos casos) ou concedida por dom divino. Este maravilhoso vai além das regras do natural porque é a consequência das ações de poderes que reconhecem sua origem no mundo sobrenatural. Pertence, portanto a outro mundo, mas, segundo as coordenadas culturais do momento, fortemente ligado à literatura agiográfica na qual o milagre entra no cotidiano e é um evento tangível, é pensado como real.

0 admirável na poesia épica e cavalheiresca italiana deriva diretamente do maravilhoso no romance medieval, no qual o mágico, o prodigioso, o monstruoso se aproximam estreitamente do aventuroso, ou das provas que 0 cavalheiro deve enfrentar para ser digno da mulher amada. De fato, se trata principalmente de um maravilhoso negativo e desviante, que cruza com o plano do real e gera as tensões que criam a trama narrativa (POIRION, 1982, BIOW, 1996 e HATHAWAY, 1968). Este maravilhoso, mais que emanação divina, é o mundo dos encantamentos e das magias que passam a interferir com as estórias dos cavalheiros. 0 romance medieval se desenvolve nas fronteiras entre o verossímil e o maravilhoso: sobre o terreno do verossímil fundamenta a estória que toma justamente das referências históricas precisas as próprias coordenadas para desenvolver em seu interior episódios inventados. Mas sobre o terreno do maravilhoso tece as aventuras com encontros de personagens imaginários, às vezes construídos com a agregação de elementos naturais com outros inventados, ou com o uso de objetos de fadas ou com propriedades mal-assombradas ou o desvio para lugares sujeitos a encantamentos.

Estas estórias, que frequentemente retomam topoi como 0 castelo encantado, o anel que torna invisível, o filtro mágico, a chegada de seres monstruosos, entram na literatura italiana através da vulgarização dos romances franceses do ciclo arturiano e bretão, a Tavola ritonda ("Távola redonda") e o Tristano riccardiano, mas tiveram rapidamente um desenvolvimento autônomo com a literatura francovêneta, os romances de Andrea da Barberino (Reali di Francia, Guerrin Meschino, etc), os cantos da espécie do ciclo de Rinaldo, até os poemas do final do Quatrocentos que assinalam uma renovação do gênero, Morgante de Pulci e Orlando innamorato de Boiardo. Todos estes poemas cavaIheirescos são baseados em episódios mágicos, caracterizados pelos mesmos modelos repetitivos.

Tomemos o ápice desta literatura cavalheiresca, Orlando furioso de Ariosto. Sabe-se que este é construído sobre eventos históricos (as investidas de Orlando em defesa da Europa contra a invasão sarracena), nos quais interagem elementos mágico-fantásticos. Os episódios mágicos buscam sublinhar a imprevisibilidade, a surpresa, que estão sempre prontos a perturbar a vida, às vezes causando reviravoltas nas resoluções, outras vezes desviando o herói de seu percurso, porém pertencentes à história, revelando desdobramentos éticos ou o imaginário mais recôndito. 0 leitor é levado a aceitar não somente o exagero do gesto de tal cavalheiro, mas ainda as várias invenções das quais a estória é constituída, porque o autor repetidamente proclama ter como fonte Turpino, ${ }^{31}$ que configura uma forma de amenizar para o leitor a (in)credibilidade da narração. 0 fundamento é uma invenção, portanto o código de pertencimento das aventuras daqueles personagens, que derivam da história verdadeira, como Orlando, ou de uma estória mítica, como Ruggiero, é um código fantástico. Quem faz as magias são precisamente os mágicos, do mago Atlante que age em combate com espíritos infernais, à maga Melissa que opera sob a tomba sacra de Merlin, "que sempre a verdade prediz" 32 (ARIOSTO, 1976, p.12); da maga Alcina, emblema da tentação sensual à "fada sábia" ${ }^{33}$ Logistilla (ARIOSTO, 1976, VIII, p.19).

0 primeiro, mas também o mais fascinante evento maravilhoso é o que ocorre no castelo de Atlante, o mago, tutor de Ruggiero que quer defendê-lo do matrimônio com Bradamante, depois do qual ele deverá morrer, e assim o atrai repetidamente a um castelo feito do nada, no qual tenta detê-lo com o fascínio do prazer.

Em todo o evento o ingrediente mágico é determinante, 0 próprio mago não é uma alma que retorna entre os vivos, mas personagem que age coerentemente com a própria natureza, em combate com o demoníaco. De fato, o seu admirável palácio é obra dos demônios: "os demônios industriosos, / com fumegantes magias e sagradas palavras, / todo de aço cingiram o belo lugar, endurecido com o fogo de Stix" ${ }^{34}$ (ARIOSTO, 1976, II, 42). 0 seu ato causa tantas incertezas a ponto que ao narrá-lo surge a dúvida se é ao menos crível: "eu o vi, eu o conheço, nem seguro estou mais / de dizê-lo aos outros; que esta maravilha / ao falso mais que ao verdadeiro se assemelha" ${ }^{35}$ (ARIOSTO, 1976, II, 54). Os castelos de Atlante são na realidade douradas prisões, nas quais ele quer manter Ruggiero com as delícias, e junto com ele, para não deixá-lo só, também outros cavalheiros.

0 segundo castelo de Atlante, no qual cai também Orlando, é descrito em seu funcionamento.

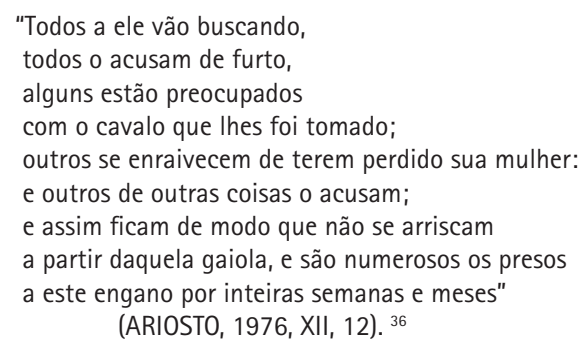

0 castelo, portanto é o encanto das imaginações pessoais de cada ser humano que permanece prisioneiro de seus desejos e de suas fantasias, também inatingiveis, dos quais não sabem separar-se. A magia de Ariosto é uma "manipulação dos fantasmas," como em toda magia renascentista 
"se volta em primeiro lugar à imaginação humana, na qual tenta suscitar impressões persistentes" ${ }^{37}$ (CULIANO, 2006, p.7). 0 castelo é, portanto o emblema da imaginação que isola o ser do resto da vida e o torna prisioneiro de uma "não-vida", preso a desejos inatingíveis porque frutos de uma vontade obstinada. Ainda que idealizado para salvar Ruggiero de uma morte prematura, no fundo o castelo de Atlante parece como o lugar de uma morte em vida, um lugar fora do tempo onde quem entra não consegue sair porque escuta somente seus fantasmas interiores.

0 maravilhoso é, portanto, uma auto-revelação, um autoconhecimento, como no fundo é também o maravilhoso que se revela a Astolfo em sua viagem à lua. 0 que se encontra sobre o satélite alcançado num vôo sobre 0 hipogrifo? ${ }^{38}$ Nada mais além dos impossiveis sonhos humanos atrás dos quais a humanidade perde seu tempo, todos os auto-enganos criados nos séculos e nas sociedades (ARIOSTO, 1976, XXXIV, 70-87).

Deste gênero de maravilhoso nasce o fabuloso. Também este, no fundo, é uma herança do mágico cavalheiresco e medieval que, no entanto, se isola do real e do verossímil para constituir um código bem coerente, no qual o maravilhoso dita as leis. É justamente na idade da nova ciência que se desenvolve o fabuloso, como se o mundo, revelando melhor seus nexos causais, não reservasse mais espaço para o maravilhoso no verossímil. Também o romance se transforma e do romance cavalheiresco desenvolve-se o romance moderno, em prosa, em direção a possíveis itinerários. Se a justaposição ao realismo é determinante naquela que é a forma picaresca das aventuras romanescas, a narração tradicional ligada à modalidade da pesquisa, da viagem e do amor, tenta usar menos dos expedientes do maravilhoso que eram os encantamentos.

A viagem tem sempre sido uma fonte de estupor e de maravilha porque coloca o indivíduo em face do desconhecido, seja este constituído de fenômenos da natureza, ou de características dos seres humanos e suas condições de vida. A literatura clássica já fornece uma reserva extraordinária de mirabilia que a Idade Média mantém viva. 0 mirabilia urbis Romae (As maravilhas da cidade de Roma) é justamente um meio para guiar o peregrino através da cidade à descoberta das ruínas que tornam Roma mais admirável que todas as outras. Mas é a viagem em áreas não antes experimentadas que constituem verdadeiras minas do maravilhoso. 0 Milione ${ }^{39}$ de Marco Polo foi conhecido também e, sobretudo como "o livro no qual se contam as maravilhas do mundo" ${ }^{40}$ e de fato desde o início se anuncia que nele se encontram "todas as maravilhas e grandes diversidades das terras da Armênia, da Pérsia e de Tartária, da Índia e de muitas outras províncias" ${ }^{41}$ (POLO, 1993, p.3). Não sabemos se foi Marco Polo que deu tal importância aquilo que tinha visto ou se o fez seu escrivão, Rustichello da Pisa, autor de versões re-editadas de romances franceses, do ciclo arturiano, habituado à narração de prodígios e de aventuras excepcionais. De qualquer modo, o texto dá relevo ao viajante
Marco Polo, porque "homem algum de geração alguma viu ou buscou tantas maravilhosas coisas do mundo." 42 Em outra iniciativa literária da escrita que se realiza entre as paredes de uma cela da prisão de Gênova, ${ }^{43}$ esta iniciativa é justamente atribuída a quem fez as viagens: "E no entanto, disse a si mesmo, que grande desventura seria se ele não colocasse por escrito todas as maravilhas que havia visto porque quem não as conhece, por este livro se lhes revelariam". ${ }^{44}$

Não somente ressurgem como motivo recorrente as expressões è una maraviglia a credere ("é uma maravilha de acreditar") ou è una maraviglia a vedere/udire ("é uma maravilha de ver/escutar") ou trovare maraviglia (encontrar maravilha) ou fare grande maraviglia ("fazer grande maravilha") pelas coisas que os viajantes encontram, mas às vezes o evento que deve ser contado é introduzido pela expressão: "contar-Ihes-ei um maravilhoso evento que ocorreu." ${ }^{45}$ Neste caso, Marco Polo relata eventos miraculosos, que se referem à comunidade cristã que os Polo encontraram em sua viagem. Trata-se num dos casos de uma montanha que se desloca. Os cristãos de Bagdá ameaçados pelo califa que se não ocorresse o que se lê no Evangelho - ou seja, que basta uma fé tão pequena como um grão de mostarda para que Deus desloque uma montanha - ele mandaria matar a todos. Assim sob a liderança do arcebispo, homem santo, e pelas preces de um sapateiro, depois da procissão, "estando os cristãos diante da cruz ajoelhados, rogando a Deus por este fato, a montanha começou a se agitar e a se mover" (POLO, 1993, p.19). ${ }^{46}$ Outros são os milagres provocados pelo corpo de São Tomás, que cura todos os enfermos de febres por meio da terra vermelha onde está sepultado. Mas a maravilha não é somente o milagre, é também, em Marco Polo, o encantamento operado pelos astrólogos que conseguem manter longe a chuva e o mau tempo do Palácio do Grã Kan ou pode ser a coragem e habilidade excepcional de cães adestrados que se arriscam a matar um leão ou ainda a existência de uma árvore que dá a farinha com a qual se pode fazer "muitos comer macarrão e boa comida" (POLO, 1993, p.131). ${ }^{47}$

Nestas poucas páginas, certamente não exaurimos completamente a modalidade do maravilhoso literário italiano. Na relação sobre "maravilha e conhecimento," falaremos ainda do mote de espírito e do engenho verbal, que possuem um destaque particular próprio da era barroca. Mas deixaremos de fora muitas outras formas, como, por exemplo, as maravilhas do teatro e do espetáculo, que na época barroca alcança sua codificação e conquista de espaços importantes no imaginário italiano com o uso de surpreendentes máquinas, música, coros e cantos. 0 teatro é, talvez, o setor que melhor conjuga a busca exasperada do novo com o surpreendente e maravilhoso barroco. Este é outro gênero do maravilhoso, que é percebido na revelação do processo de ilusão - criado pelas cenas - e desilusão - com a compreensão de que tudo é falso -, essencial para o imaginário da época. A ilusão do espetáculo encarna bem o senso profundo da maravi- 
Iha barroca: não somente busca o novo e surpreendente, mas também é máscara de uma perda cósmica, que leva a uma forma de dúvida sistemática e a uma crise profunda que toca a consciência européia no final do século.

Battistini escreve que aquilo que estimula o homem barroco "na busca de novos territórios é a consciência de sua própria natureza mutante, portanto sempre surpreendente, numa instabilidade sem trégua" (BATTISTINI, 2000, p.52-52). ${ }^{48} 0$ barroco de fato é também a época na qual a própria vida é representada segundo a metáfora do mundo como teatro, que sublinha o quanto de provisório e de incerto se esconde atrás da surpreendente maravilha de sua palavra e de sua arte.

\section{Referências}

ARISTÓTELES. Etica.Trad. italiana Armando Plebe. Bari , Laterza, 1983.

AUERBACH, E. Mimesis. II realismo nella letteratura occidentale, trad. it. de A. Romagnoli e H. Hinterhäuser, Torino, Einaudi, 1979.

ARIOSTO, I, Orlando furioso, ed. C. Segre, Milão, Mondadori, 1976, III.

BATTISTINI, A. Paradiso infernal, celeste inferno". Ossimori d'amore nell'"Adone" di Giovan Battista Marino, RiLUnE, 7, 2007, p.167-183:172.

. Il Barocco: Cultura, miti, immagini. Roma, Salerno, 2000, p.51-2.

BIANCONI, L. II Seicento, Torino, EDT, 1991.

CULIANO, F. Eros e magia nel Rinascimento. Torino, Bollati Boringhieri, 2006.

DANTE ALIGHIERI. Convivio, ed. C. Vasoli e D. De Robertis, in Opere minori, I.II, Milão-Nápolis, Ricciardi, 1988, IV, XXV. Paradiso, ed. A.M. Chiavacci Leonardi,Milano, Mondadori, 1997. Purgatorio, ed. A.M. Chiavacci Leonardi,Milano, Mondadori, 1994. Vita nuova ed. G. Gorni, Torino, Einaudi, 1996, I.

BIOW, D. 'Mirabile Dictu. Representations of the Marvelous in Medieval and Renaissance Epic', Ann Arbor, Michigan University Press, 1996.

HATHAWAY, B. Marvels and Commonplaces. Renaissance literary criticism, New York, Random House, 1968.

MARINO, Giambattista. Opere, Ed. A. Asor Rosa, Milano, Rizzoli, 1967.

Lettere, ed. M. Guglielminetti, Torino, Einaudi, 1996.

L'Adone, ed. G. Pozzi, Milano, Mondadori, 1976, VI, 173-4.

Rime, parte seconda, ed.i M. Slawinski, San Mauro, RES, 2007, I.

MURTOLA, G. Della creazione del mondo, Veneza, Deuchino e Pulciani, 1608.

POIRON, D. Le merveilleux dans la littérature francaise du Moyen Age. Paris, PUF, 1982.

POLO, M. II Milione, Milano, Garzanti, 1993.

0 livro das maravilhas. Trad. Elói Braga Jr. Porto Alegre: L\&tPM Pocket, 1985.

SINGLETON, C. Saggio sulla "Vita nuova, trad. it. de G. Pampaloni, Bolonha, II Mulino, 1968. 


\section{Notas}

1 divenuta parola che suona, si trasforma nella musica e nel canto

2 far nascere la meraviglia

3 dinotar maggiormente la Provvidenza di Dio

4 FISCHIATA XXXIII

$\dot{E}$ del poeta il fin la meraviglia

(parlo de l'eccellente, non del goffo),

chi non sa far stupir vada alla striglia.

lo mai non leggo il cavolo ed il

carcioffo,

che non inarchi per stupor le ciglia,

com'esser possa un uom tanto gaglioffo.

5 lo pretendo di saper le regole più che non sanno tutti i pedanti insieme, ma la vera regola (cor mio bello) è saper rompere le regole a tempo e luogo.

6 I poeti che dettano rime senza vivezze, fabbricano cadaveri, non poesie.

7 di brilli di poesia viva

8 morbido, vezzoso ed attrattivo

9 morbide tenerezze

10 L'ADONE

Lince privo di lume, Argo bendato,

vecchio lattante e pargoletto antico, ignorante erudito, ignudo armato, mutolo parlator, ricco mendico, dilettevol error, dolor bramato, ferita cruda di pietoso amico, pace guerriera e tempestosa calma, la sente il core e non l'intende l'alma. Volontaria follia, piacevol male, stanco riposo, utilità nocente, desperato sperar, morir vitale, temerario timor, riso dolente, un vetrro duro, un adamante frale, un'arsura gelata, un gelo ardente, di discordie concordi abisso eterno, paradiso infernal, celeste inferno.

11 non risponde soltanto al gusto barocco per le efflorescenze verbali e per i cataloghi indefiniti, ma anche alla natura polisemica di ciò che Marino cerca di definire

12 il suo immenso successo musicale proprio alla temperata 'mediocrità' delle sue invenzioni concettose e metaforiche

13 "Ecco l'ora, ecco ch'io

(a pena il posso dire)

son costretto al partire.

Dammi, Lidia, cor mio,

I'ultimo bacio, omai, I'ultimo a Dio":

Cosi dico io partendo,

ella tace piangendo,

ella tace e io piango,

ella vien meno ed io seco rimango.

14 massimamente necessaria al buono fondamento de la nostra vita

15 "[...] a questa etade è necessario d'essere reverente e disidiroso di sapere; a questa etade è necessario d'essere rifrenato, si che non transvada; a questa etade è necessario d'essere penitente del fallo si che non s'ausi a fallare.

16 uno stordimento d'animo per grandi e maravigliose cose vedere o udire o per alcuno modo sentire: che, in quanto paiono grandi, fanno reverenti a sé quelli che le sente; in quanto paiono mirabili fanno voglioso di sapere di quelle.

17 questa angiola giovanissima

18 io nella mia puerizia molte volte l'andai cercando, e vedeala di si nobili e laudabili portamenti, che certo di lei si potea dire quella parola del poeta Homero: 'Ella non parea figliuola d'uomo mortale ma di Dio.

19 il savio

20 padre suo e degli altri poeti

21 tenne d'angiol sembianza / che fosse del Tuo regno

22 angiola giovanissima

23 per far cosa nova

24 E chi volesse sottilmente considerare, quella Beatriz chiamerebbe Amore per molta somiglianza.

25 amor che move il sole e l'altre stelle.

26 Angelo clama in divino intellecto / e dice: 'Sire, nel mondo / si vede maraviglia nell'acto che procede / d'un'anima che infin qua su risplende.

27 N.T. : Abreviação de "Madonna," título que no final da Idade Média se utilizava antes do nome.

28 lo vidi monna Vanna e monna Bice / venire inver' lo loco là ov'io era, / I'una appresso dell'altra maraviglia. 
29 Diceano molti, poi che passata era: "Questa non è femina, anzi è de' bellissimi angeli del cielo". E altri diceano: "Questa è una maraviqlia; che benedecto sia lo Signore che si mirabilmente sa operare!". Io dico che ella si mostrava si gentile e si piena di tutti li piaceri, che quelli che la miravano comprendeano in loro una dolcezza onesta e soave tanto, che ridire no.llo sapeano; né alcuno era lo quale potesse mirare lei, che nel principio nol convenisse sospirare. Queste e più mirabili cose da.llei procedeano virtuosamente. Onde io pensando a.cció, volendo ripigliare lo stilo della sua loda, propuosi di dicere parole nelle quali io dessi ad intendere delle sue mirabili ed excellenti operationi [...].

30 che par cosa venuta / da cielo in terra a miracol mostrare.

31 Turpino, em latim Turpinus ou Tylpinus, foi eleito arcebispo de Reims em 774. Uma lenda diz que Carlos Magno o levou em Campanha na Espanha contra os muçulmanos. Foi-lhe atribuido erroneamente a Historia Karoli Magni et Rotholandi. Ariosto o toma como fonte de todas as lendas da era cavalheiresca.

32 che sempre 'I ver predisse

33 fata saggia

34 i demoni industri, / da suffumigi tratti e sacri carmi, / tutto d'acciaio avean cinto il bel loco, / temprato all'onda et allo stigio foco.

35 io 'I vidi, io 'I so; né m'assicuro ancora / di dirlo altrui; che questa maraviglia / al falso più ch'al ver si rassimiglia io 'I vidi, io 'I so; né m'assicuro ancora / di dirlo altrui; che questa maraviglia / al falso più ch'al ver si rassimiglia.

36 Tutti cercando il van, / tutti gli danno colpa di furto alcun che lor fatt'abbia / del destrier che gli ha tolto altri è in affanno; / ch'abbia perduta altri la donna, arrabbia; / altri d'altro l'accusa: e cosi stanno, / che non si san partir da quella gabbia; / e vi son molti, a questo inganno presi, stati le settimane intiere e i mesi.

37 si rivolge in primo luogo all'umana immaginazione, nella quale tenta di suscitare impressioni persistenti.

38 N.T.: Animal fabuloso, criado por Ariosto: uma mescla de cavalo alado com cabeça de águia.

39 Este livro foi traduzido no Brasil como 0 livro das maravilhas.

40 II libro [...] dove si raccontano le meraviglie del mondo.

41 tutte le maraviglie e gran diversitadi delle terre d'Erminia, di Persia e di Tarteria, d'India e di molte altre provincie.

42 niuno uomo di niuna generazione non vide né cercò tante maravigliose cose del mondo.

43 N.T.: Marco Polo esteve na prisão em Gênova junto com o escrivão Rustichello.

44 "E però disse infra se medesimo che troppo sarebbe grande male s'egli non mettesse per iscritto tutte le maraviglie ch'egli ha vedute, perché chi non le sa l'appari per questo libro".

45 dirovvi d'una maraviglia che avvenne

46 istando li cristiani dinanzi a la croce in ginocchioni pregando ldio di questo fatto, la montagna cominciò a ruvinare e mutarsi. Li saracini, vedendo ciò si maravigliaro molto, e 'l califfo si convertio e molti saracini.

47 molti mangier di pasta e buoni

48 nel frugare nuovi territori è la coscienza della sua stessa natura cangiante, dunque sempre sorprendente, nell'instabilità senza tregua

Erminia Ardissimo ensina Literatura italiana na Universidade de Torino. Obteve o título de Doutora na Universidade de Yale e na Universidade Católica do Sacro Cuore em Milão. Publicou diversos ensaios sobre Dante, Petrarca, o Humanismo, Tasso, Literatura Barroca italiana, Manzoni, etc. Autora de diversos livros: "L'aspra tragedia," Poesia e sacro in Torquato Tasso (1996); Tasso, Plotino, Ficino; In margine a un postillato (2003); II Barocco e il sacro. La predicazione del teatino Paolo Aresi tra letteratura, immagini e scienza (2001); II Seicento, (2005); Tempo liturgico e tempo storico nella "Commedia" di Dante (2009). Foi editora de Poemi biblici del Seicento (2005), Trattato delle acutezze di Matteo Peregrini (1997), e uma seleção de cartas de Galileu (com comentários, 2008). Com Sabrina Stroppa escreveu Leggere testi letterari (2001). Recebeu um prêmio da Italian Academy for Advanced Studies at Columbia University Fellowship (Primavera 2009) por sua pesquisa sobre The Emergence of Modernity in 17th Century Italian Literature.

Silvana Scarinci estuda a música dos séculos XVI e XVII, principalmente a música vocal italiana, sob perspectivas interdisciplinares, com ênfase em literatura, gênero e a tradição clássica. Publicou o livro acompanhado de CD, Safo Novella: uma poética do abandono nos lamentos de Barbara Strozzi (Veneza, 1619 - 1677) (EDUSP e ALGOL editoras, 2008). É uma ativa alaudista, dedicando-se principalmente aos repertórios dos séculos XVI e XVII inglês, italiano e francês. É professora do curso de graduação e pós-graduação em música da UFPR. 